\title{
A SYSTEM DYNAMICS MODEL FOR URBAN TAXI PRICE SIMULATION
}

\author{
Shi AN, Xiaowei HU, Jian WANG, Hang LV \\ School of Transportation Science and Engineering, Harbin Institute of Technology, China
}

Submitted 9 March 2018; resubmitted 18 April 2019, 6 June 2019; accepted 4 July 2019

\begin{abstract}
Urban taxi services have been developing year on year, playing an increasingly important role in the economy and the transportation markets of each city. This increases interest in measuring their performance. This paper analysed the relationship among the four stakeholders (including administrative department, operational companies, taxi drivers and customers) for urban taxi passenger transport system in China, and applied System Dynamics (SD) model to explore the dynamic characteristics of urban taxi price system. The main achievements of this paper are as follows, firstly, this paper adopted stakeholder mapping to describe the relationships among the four stakeholders. Then analysed the causal flow diagrams and the different variables of urban taxi passenger transport system operation, and presented the SD model, which considers factors that affect the taxi operation. With the combination of taxi operation data of Harbin city, we simulated eleven urban taxi operation scenarios and proposed kinds of suggestions to improve urban taxi passenger transport system operation, which can provide a good basis for recommending policy decisions for urban taxi market.
\end{abstract}

Keywords: urban taxi, system dynamics, scenario analysis, stakeholders, performance analysis.

\section{Introduction}

As an indispensable part of the urban passenger transport system, taxi plays an important role in offering personalized services for passengers, and bridges the gap between personal and other public transport services (Han 2010). Taxis can not only provide convenient, flexible and fast transportation services for passengers, but also can satisfy passengers' privacy requirements.

With the rapid acceleration of China's urbanization and motorization process, the demand of taxi increases rapidly in many cities in China. Taking Harbin as an example, the number of registered taxi in Harbin had changed from 10411 vehicles in 2000 to 15699 vehicles in 2017, which increased by $50.8 \%$; meanwhile, taxi carries about 700000 passengers per day, which is comparable to one third of the number of trips occurring in the bus system.

Urban passenger transport system includes three stakeholders, and they are administrative departtment, operational companies and customers (Van de Velde 1999; Roumboutsos, Kapros 2008). However, there are four stakeholders in the urban taxi passenger transport system in China, which includes administrative department, operational companies, taxi drivers and customers. How to dissect the relationship among these four categories of stakeholders is a core issue in modelling urban taxi operation research.

Taxi service is related with efficiency and performance, and there are methods to measure the performance in the economy and the transportation markets (Simões, Marques 2010). In addition, taxi service has environmental and social negative externalities, such as air pollution emission and noise (An et al. 2011). During the past decade, researchers usually adopt social welfare maximization and average cost pricing (the second best social optimum) to analyse taxi pricing (Wang, Chen 2004), which involves the interest of administrative department, operational companies, taxi drivers and customers. Therefore, how to analyse the dynamic and complexity of the urban taxi price system is an interesting issue.

This paper aims to improve the urban taxi price system by integrating the System Dynamics (SD) approach and the domain knowledge in transportation. The contributions of this paper are threefold. First, we analyse the relationship among the urban taxi passenger transport system's four categories stakeholders. Hence, a SD approach is adopted to analyse the operation of urban taxi price system. Besides, authors also propose kinds of management policy advice for the taxi operation and development.

${ }^{*}$ Corresponding author. E-mail: xiaowei_hu@hit.edu.cn 
The structure of this paper is as follows:

") section 1 reviews relevant research related to taxi operation, and SD theory application in the transport field;

"» section 2 analyses the relationship among the four categories stakeholders; then the SD model for urban taxi price system is established;

"» section 3 provides the simulation and results of the taxi operation based on the Harbin taxi operation data, and some related discussions;

"» last section is the conclusions.

\section{Literature review}

\subsection{Review of modelling urban taxi service}

Urban taxi is an important part of the urban passenger transport system; and the economics of taxi service has been examined in an aggregated manner (Wang 2011). De Vany (1975) adopted taxi vacant ratio and occupied ratio to reflect the taxi supply and customer demand, these two parameters then be regarded as the key elements in the taxi market equilibrium. In 1990s, the notable researches on taxi service have made conspicuous progress in the taxi market mechanism (Arnott 1996; Cairns, Liston-Heyes 1996). In the meantime, there were many contributions to the taxi regulation/deregulation around the world (Häckner, Nyberg 1995; Gärling et al. 1995; Dempsey 1996; Gaunt, Black 1996; Morrison 1997; Schaller 1999).

During the past decade, Yang et al. $(2002,2005)$ have made prominent studies on taxi service. In recent years, Yang et al. (2010) had studied the competitive equilibrium of bilateral urban taxi-customer searching and meeting behaviour service; then they analysed the equilibrium properties of taxi market with search frictions, and found that the taxi utilization ratio and the customer waiting/ searching time (or service quality) were proved to be constant along the Pareto frontier (Yang, H., Yang, T. 2011).

Taxi fare is an important element in taxi market operation and development. Han (2010) reported that the taxi fare in Singapore was cheaper by international standards, which resulted in a lower vehicles taxes and fuel taxes; and the major problem of taxi services in Singapore was the imbalance of taxi supply and customer demand. According to the production prices theory, urban taxi fares are in accordance with the cost plus profit in China. However, the average social profit is only a market competition trend, which cannot be known on funds. As a result, urban taxi fare is formulated and implemented by urban Price Bureau, and has to be examined and approved by the urban People's Government in China (Lv 2011).

On the whole, modelling urban taxi service is a worthwhile issue to be analysed and computed by economists, geographer and transportation researchers (Cooper, Mundy 2010; Kim et al. 2011; Qian, Ukkusuri 2015; Drăgoicea et al. 2015). The taxi service market as a dynamic and complexity system, it should be analysed from a multi-stakeholder optic viewpoint.

\subsection{Review of SD theory application in transport field}

There are many uncertain factors in urban taxi system's development and evolution process, such as economic factors, social factors, environmental factors, demographic factors, cultural factors and policy factors. Urban taxi system is a multi-variable, multi-stakeholder and multiple feedback complex system. With the increasing of resident's income, the changing of fuel prices and the implementing of fuel surcharges will affect the urban taxi system.

$\mathrm{SD}$ is designed to explore problematic behaviour patterns caused primarily by the feedback structures of the setting (Barlas 2007). SD can handle multi-variables, multiple feedback and nonlinear time-varying complex problems, which combine the qualitative and quantitative analysis. The implication of SD theory in transport field first dated from the research of Drew (1990), and Abbas, Bell (1994).

In order to acquire a good understanding of different transportation policies, many researchers have adopted the SD approach to model transportation problems. Different authors who apply SD have achieved more useful research achievements (Haghani et al. 2002; Federici et al. 2003; Han, Hayashi 2008; Hang, Li 2010; Liu et al. 2010; Minato, Morimoto 2011).

Though modelling urban taxi service and application of SD in the transport field have proliferated in recent years. Many researchers have made progress in solving transportation problems with the SD approach. However, effort is still lacking in analysing the relationship among the different categories stakeholders, especially in evaluating the dynamic and complexity of urban taxi system. In existing studies, only Han et al. (2010) mentioned and took the relationship among the different stakeholders as a key role in the taxi service, but he did not consider the dynamic feature in modelling taxi operation. This paper attempts to fill these research gaps as it develops a taxi operation model based on SD approach.

\section{The SD model of urban taxi price system}

\subsection{Relationship analysis among different stakeholders}

As mentioned above, there are four stakeholders in urban taxi passenger transport system in China, including the administrative department, operational companies, taxi drivers and customers. Customers pay for the taxi service and want to enjoy the satisfying and efficient service; taxi drivers desire to improve their income and ensure their lawful rights and interests; the operational companies concern about economic benefits and profits; the government (administrative department) requires the taxi market developments and social benefit.

Based on the research of Wang (2009), this paper adopted stakeholder mapping to explore the relationship among kinds of stakeholders of urban taxi passenger transport system, which first combines the four stakehold- 
ers of the urban taxi passenger transport system into the taxi market benefits distribution relationship. Figure 1 sketches these relationships.

In Figure 1, under the premise of the stable of urban taxi market and the prior explicit of profit distribution, customers pay the taxi transportation service, the administrative department, operational companies and taxi drivers would not have conflict on the interest. However, there are uncertainty risks and competitions with other passenger transport (bus or subway) in the market, which makes it difficult to guarantee the stability of the operating income in the urban taxi market. The administrative department and operational companies still obtain a fixed amount of profit; this risk is then fully transferred to the taxi drivers.

At present, it does not consider customers benefit in the taxi pricing process, so this paper takes the relationship among the taxi system's stakeholders as a sub-system in the SD model, which can fully take account the effect of relationship among of the urban taxi passenger transport system's stakeholders to the taxi operation.

\subsection{The objective of the SD model}

The main objective of the SD model of urban taxi system is to explore the evolutionary relationship between taxi pricing and different categories stakeholders' benefit distribution, discuss the rationality of the taxi pricing under the balance between taxi supply and customer demand, and analyse the effect of taxi development policy by scenario simulation. The specific objectives of the SD model of urban taxi system are as follows:

"» analyse the evolution process of taxi pricing and establish the causal feedback relationship among the social-economic, taxi supply, customer demand, taxi operation and taxi development policy;

"» according to the urban social-economic development and taxi system current situation, as well as the taxi development policy, simulate different taxi development policy scenarios and analyse the implementation effects on the taxi market development;

"» dissect the different categories stakeholders' benefit distribution and establish the balance benefit distribution mechanism among the administrative department, operational companies, taxi drivers and customers.

\subsection{Module structure of the SD model of urban taxi system}

The module of the urban taxi SD model has six main parts, including social-economic module, taxi supply module, customer demand module, taxi operational status module, taxi development policy module and taxi stakeholders module. Figure 2 gives the outline of the module relationship of the SD model of urban taxi system.

The social-economic module describes the influence of the social-economic development on number of taxi, residents' income and demand; the taxi supply module describes the taxi investment and the number of taxi ve-

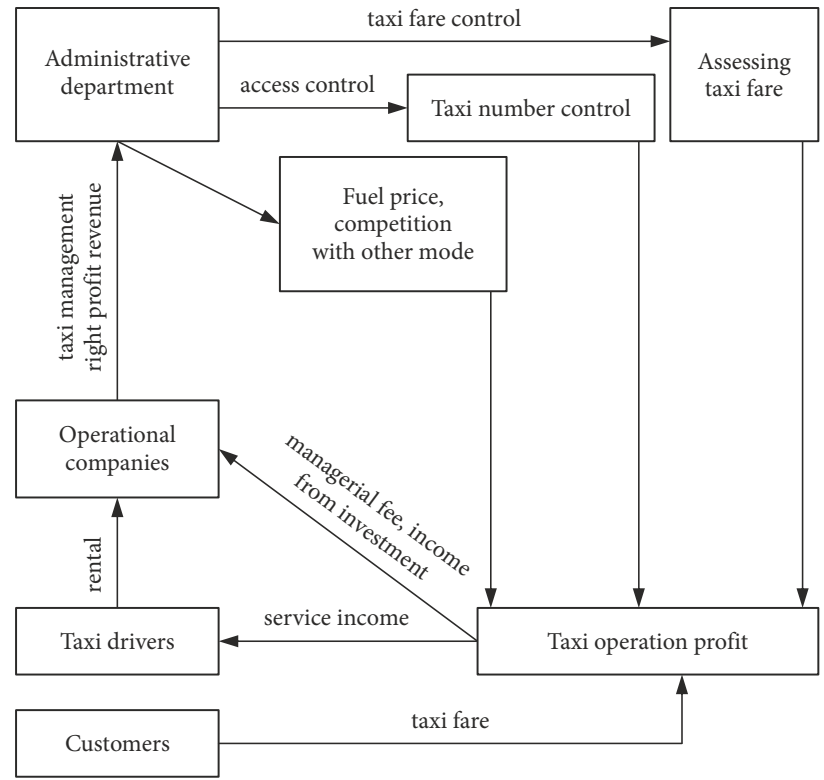

Figure 1. Urban taxi market benefits distribution relationship chart

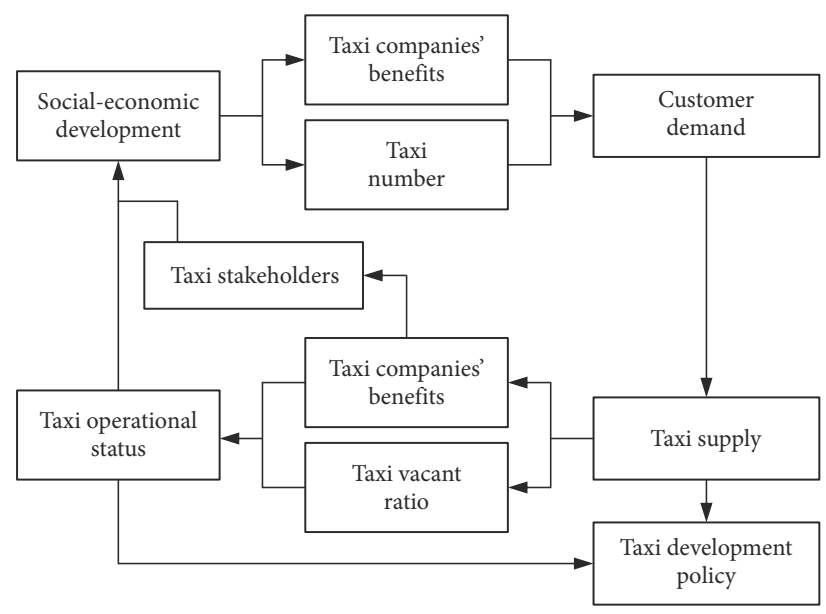

Figure 2. The module relationship of the SD model of urban taxi system

hicles; customer demand module describes the residents' income and population; taxi operational status module describes the taxi vacant ratio and the taxi companies' benefits; taxi development policy module describes the policy measures effects and associated parameter changes; taxi stakeholders module covers the administrative department, operational companies, taxi drivers and customers, the main part is the benefits distribution relationship.

\subsection{The system flow diagram of the SD model of urban taxi system}

Based on above analysis, this paper established the causal relationship diagram and the system flow diagram of the SD model of urban taxi system, Figure 3 was proposed path diagram for the general model applied. The parameter estimation diagram of the SD model of urban taxi system can be seen in Section 2.5. 


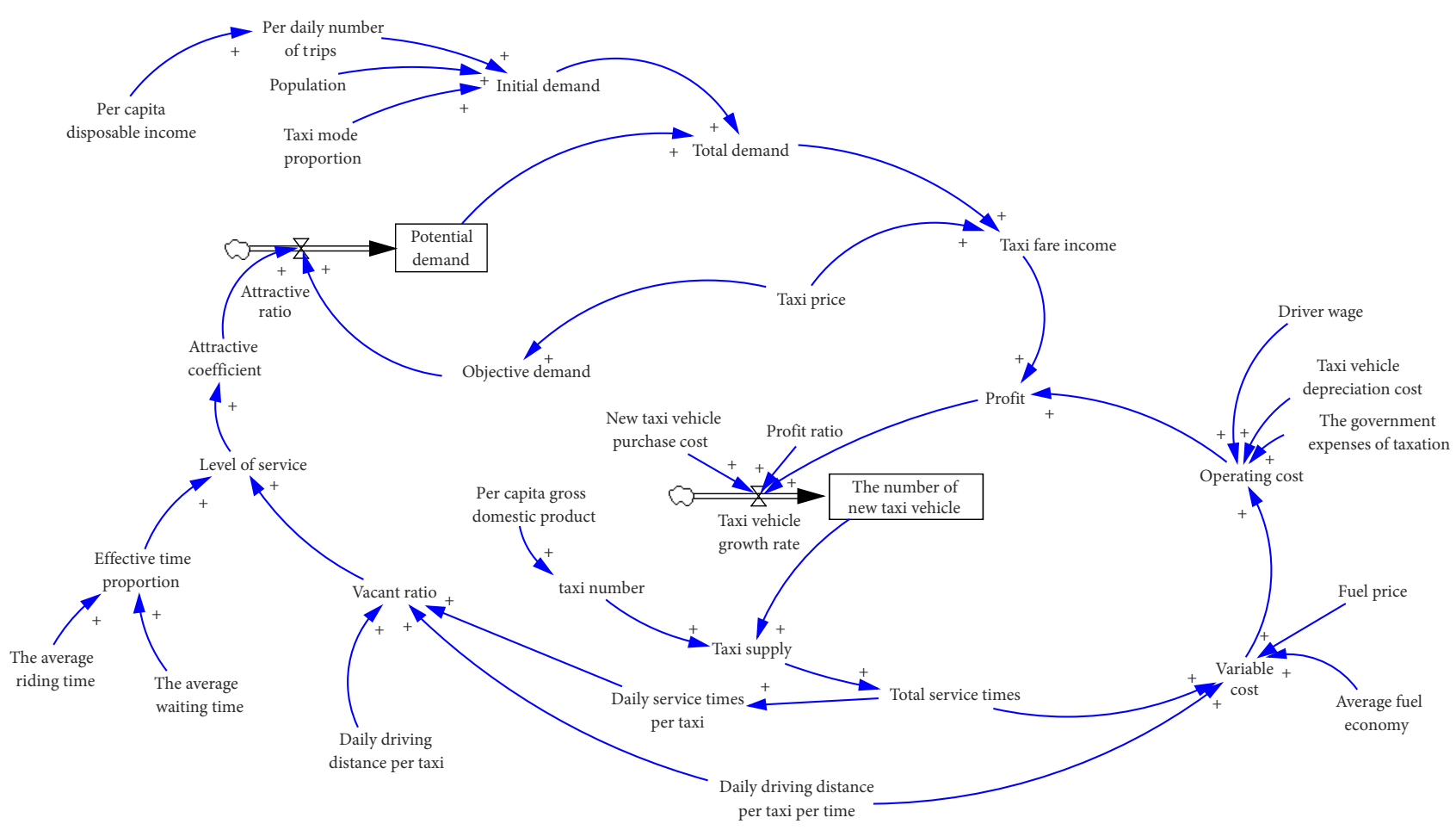

Figure 3. The system flow diagram of the SD model of urban taxi price system

In the system flow diagram of the SD model of urban taxi system, the level models included the "potential demand" and "the number of new taxi vehicles", which represented taxi passenger total demand changing and taxi vehicle supply changing, respectively; and the rate models were the "attractive ratio" and "taxi vehicle growth rate". Meanwhile, we adopted "vacant ratio" and "effective time proportion" as the SD model's auxiliary models.

The main feedback loops of the causal relationship diagram are as follows:

"» the positive feedback loop: the improvement of economic development will increase the trip frequency; the population growth and resident's consumption level raise will increase taxi demand; the taxi fare increase will promote revenue increase, and thus will encourage taxi company to purchase new taxi vehicles, increase the taxi supply and the total operating frequency, while the average daily service times per taxi will also increase and the taxi vacant ratio will decrease; and then the taxi service quality will be improved and more potential customer demand will be attracted to take taxi as the transport mode, which circles a positive feedback loop;

"» the negative feedback loop: the total operating frequency rise will increase the taxi operating cost and changing cost, thereby enabling to reduce the taxi company's revenue, which is a negative feedback loop.

This paper takes the economic development, fuel prices, and driver's wage as the exogenous variables of the SD model of urban taxi system; meanwhile it takes taxi operating frequency, population as the input variables of the SD model of urban taxi system.

\subsection{The parameter estimation diagram of the SD model of urban taxi system}

We obtained data from existing resources, which is recorded for the taxi operation in Harbin, the capital of Heilongjiang province, which is located at the northeast of China. It is also the largest city in the northeast of China, which serves as a key political, economic, scientific, cultural, and communications hub in northeast of China as well as an important industrial base of the nation. The central municipal area of Harbin is $7086 \mathrm{~km}^{2}$ with a population of 5.879 million in 2010. As to simulation data, it includes three sources. The first was Harbin Statistical Yearbooks (in Chinese, available from Internet: $h t t p: / / w w w . s t a t s . g o v . c n$ ), which showed the change of number of taxi and per capita Gross Domestic Product (GDP) from 2000 to 2009. The second data source was "The Report of Harbin Taxi Operating Survey Analysis" (STSE 2009), which was commissioned by Harbin Transportation Bureau. In addition, the survey scope was $10 \%$ (there were 1337 taxi vehicles comparing with the whole number 13425 in 2008). As a result, we assume that the samples can reflect the taxi and travel behaviour in the whole city. The third data source was the residents' travel survey data of some cities in China (Song 2010).

Since the dependent variable and the independent variable are linear, and the error terms of all the observations are independent, we assume that all the error terms obey the normal distribution, that is, linear regression analysis can be applied. Through the linear regression analysis, we can draw the relationship between the annual GDP and number of taxi, and the relationship between the per capita disposable income and the number of daily of trips. Then the Auxiliary Models of the SD model of urban 
taxi system can be obtained. Adopting Vensim software (https://vensim.com) to simulate and calculate can get the effect of taxi development policy:

"» relationship between the annual GDP and number of taxi (data was shown in Table 5):

Number of taxi $=2552 \cdot \ln ($ the annual GDP $)-12819$, $R^{2}=0.924$

"» relationship between the per capita disposable income and the number of daily of trips:

The number of daily trips $=0.545 \cdot \ln$ (the per capita disposable income) -2.743 ,

$R^{2}=0.902$;

"» the basic parameters of taxi operation.

This paper adopts the taxi operation parameters of Harbin taxi in 2009 as the basic parameters, as shown in Table 1.

As is shown in Tables 1 and 2, the average taxi passenger occupancy is 1.66 person/trip, which means that passengers tend to taxi alone. As to the average riding time, it is about $11.54 \mathrm{~min}$, which shows that taxis are the means for short-distance travel in cities. The average waiting time is 5 min so there are many orders for taxis.

\subsection{The validation of the SD model}

Taking the real taxi operational data in Harbin as the input of the SD model of urban taxi system, the corresponding taxi running by the simulation of Vensim software can be calculated, and we compared the model output with the real data to judge the effectiveness of taxi price SD model.

Table 2 presented the comparison of SD taxi pricing model simulation and the real data. It can be seen that the prediction error of taxi supply, taxi vacant ratio and daily service times per taxi are all less than $4 \%$, which shows high credibility. Therefore, the SD model can be used to predict taxi operation and analysis.

\section{The case study of Harbin taxi operation}

\subsection{The basic taxi operation data in Harbin}

By inquiring and collecting the 2000 to 2009 basic statistics data from Harbin Statistical Yearbook, we obtain the basic statistics, such as population, per capita GDP, disposable income and the taxi possessive quantity, which is shown in Table 3.

\subsection{The basic scenario simulation of Harbin taxi operation}

Takes Harbin statistics in 2009 as the basic scenario, which the taxi ownership is 13425 taxi vehicles, and the initial new-increase vehicles are 1000 units, similar to the number prefigured in the 2010 Harbin new taxi increase program. We adopt the SD model of urban taxi system to simulate 60 months taxi operation in Harbin as the basic scenario.

As can be seen from the Table 4 and Figure 4, with
Table 1. The related parameters of Harbin taxi operation in 2009 (STSE 2009)

\begin{tabular}{|l|c|c|}
\hline \multicolumn{1}{|c|}{ Parameter } & Unit & Numerical value \\
\hline Start price & $¥ / \mathrm{km}$ & $8 ¥ / 3 \mathrm{~km}$ \\
\hline Distance price & $¥ / \mathrm{km}$ & 1.9 \\
\hline Fuel surcharges & $¥ /$ trip & 1 \\
\hline $\begin{array}{l}\text { Taxi vacant ratio (in terms } \\
\text { of travel distance) }\end{array}$ & - & 0.50 \\
\hline Daily service trips per taxi & trips/day & 32 \\
\hline $\begin{array}{l}\text { Daily driving distance } \\
\text { per taxi }\end{array}$ & $\mathrm{km} /$ day & 320 \\
\hline $\begin{array}{l}\text { Daily driving distance } \\
\text { per taxi per trip }\end{array}$ & $\mathrm{km} /$ trip & 4.79 \\
\hline $\begin{array}{l}\text { Average taxi passenger } \\
\text { occupancy }\end{array}$ & person/trip & 1.66 \\
\hline The average riding time & min & 11.54 \\
\hline The average waiting time & min & 5 \\
\hline Driver wage & $¥ / \mathrm{month}$ & 1800 \\
\hline $\begin{array}{l}\text { The government expenses } \\
\text { of taxation }\end{array}$ & $¥ / \mathrm{month}$ & 4500 \\
\hline Taxi vehicle depreciation cost & $¥ / \mathrm{month}$ & 1920 \\
\hline Fuel price & $¥ /$ litre & 6 \\
\hline Average fuel economy & $\mathrm{km} / \mathrm{litre}$ & 10 \\
\hline Taxi mode proportion & thousands & 4751 \\
\hline Population & & 7 \\
\hline
\end{tabular}

Note: US $1 \$=6.6 ¥$ conversion in 2009 .

Table 2. SD simulation results compared with actual data

\begin{tabular}{|l|c|c|c|c|c|}
\hline Parameter & Unit & $\begin{array}{c}\text { Simula- } \\
\text { tion } \\
\text { result }\end{array}$ & $\begin{array}{c}\text { Real } \\
\text { data }\end{array}$ & $\begin{array}{c}\text { Absolute } \\
\text { difference }\end{array}$ & $\begin{array}{c}\text { Relative } \\
\text { error } \\
{[\%]}\end{array}$ \\
\hline Taxi supply & vehicle & 13482 & 13425 & 57 & 0.4 \\
\hline $\begin{array}{l}\text { Taxi vacant } \\
\text { ratio }\end{array}$ & - & 0.484 & 0.500 & 0.016 & 3.2 \\
\hline $\begin{array}{l}\text { Daily service } \\
\text { trips per taxi }\end{array}$ & $\begin{array}{c}\text { trips/ } \\
\text { day }\end{array}$ & 33 & 32 & 1 & 3.1 \\
\hline
\end{tabular}

time going by, taxi supply, total demand, the daily service times per taxi, attractive coefficient, and level of service have all been constantly increasing, while the taxi vacant ratio has been declining during the five years.

It is easy to see from Figure 4, attractive coefficient, level of service, daily service trips per taxi and vacant ratio all vary from an existing status to a new one, especially during the taxi operational simulation's 10, 29, 45 and 60 month; these months are the time nodes of taxi operation changes. As a result, we can rely on these time nodes to help determine the implementation time of taxi development policies. Moreover, we can also find that the vacancy ratio decreases with the number of taxis increasing; one possible reason for this is that the total passenger demand growth rate is faster than that of taxi supply growth. 

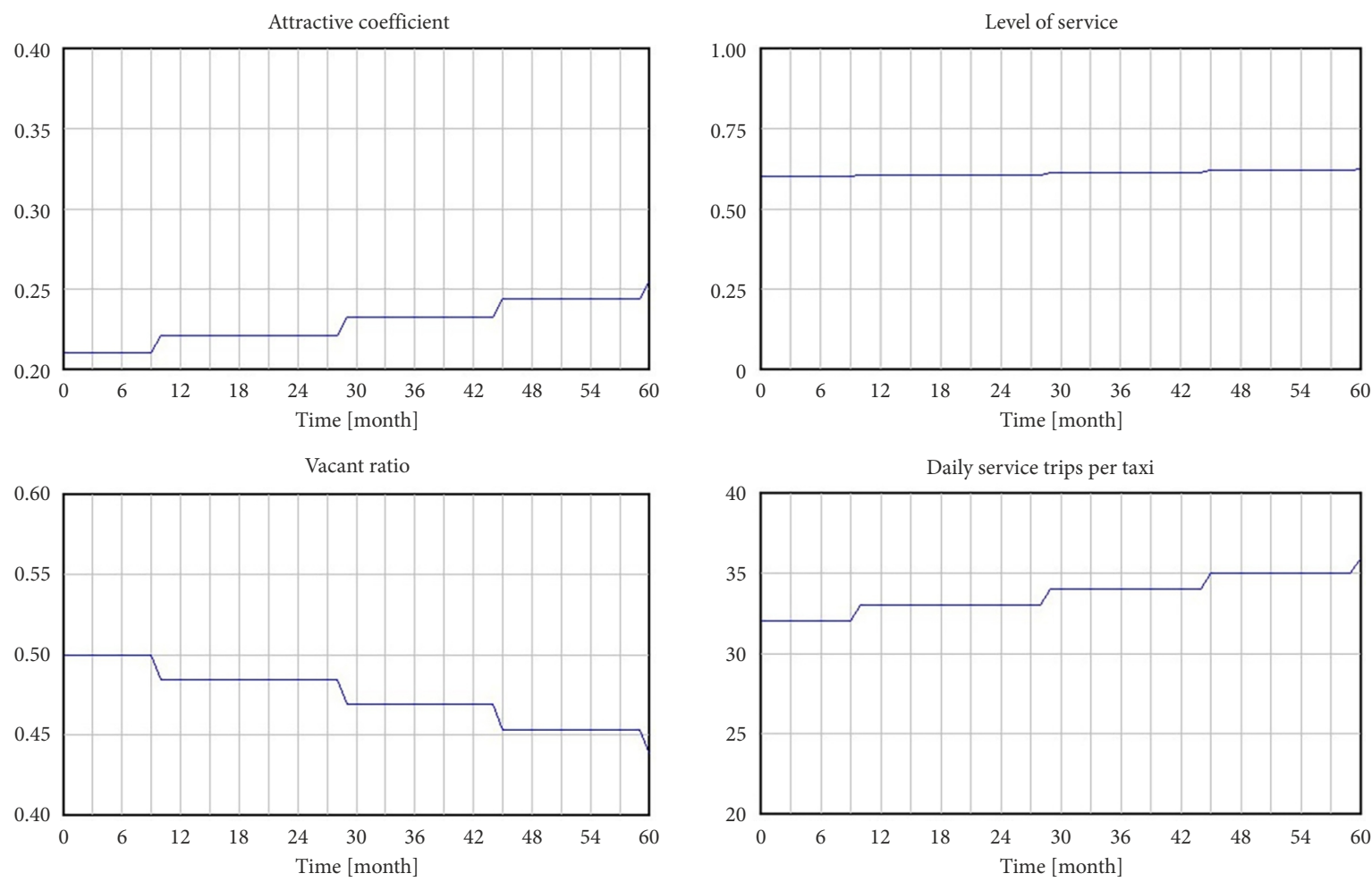

Figure 4. Simulation charts of the basal scenario of Harbin taxi operations

Table 3. The basic statistics of Harbin

\begin{tabular}{|l|c|c|c|c|c|c|c|c|c|c|}
\hline \multicolumn{1}{|c|}{ Year } & 2000 & 2001 & 2002 & 2003 & 2004 & 2005 & 2006 & 2007 & 2008 & 2009 \\
\hline Population [thousands] & 3481 & 3074 & 3118 & 3152 & 3945 & 3990 & 4727 & 4755 & 4751 & 4747 \\
\hline Per capita GDP [¥] & 10322 & 11547 & 12642 & 14252 & 16674 & 18821 & 21374 & 24768 & 29012 & 32886 \\
\hline Per capita disposable income [¥] & 5632 & 6407 & 7004 & 7907 & 8940 & 10065 & 11231 & 12772 & 14589 & 15887 \\
\hline Taxi number [vehicles] & 10411 & 11556 & 11566 & 11397 & 11551 & 12256 & 12706 & 13224 & 13425 & 13646 \\
\hline
\end{tabular}

Note: data source are from 2001 to 2010 Harbin Statistical Yearbooks.

Table 4. Simulation results of the basal scenario of Harbin taxi operations

\begin{tabular}{|l|c|c|c|c|c|c|}
\hline \multicolumn{1}{|c|}{ Parameter } & Basal year & Year 1 & Year 2 & Year 3 & Year 4 & Year 5 \\
\hline Attractive coefficient & 0.21 & 0.22125 & 0.22125 & 0.2325 & 0.24375 & 0.255 \\
\hline Level of service & 0.6 & 0.60625 & 0.60625 & 0.6125 & 0.61875 & 0.625 \\
\hline Vacant ratio & 0.5 & 0.484375 & 0.484375 & 0.46875 & 0.453125 & 0.4375 \\
\hline Daily service trips per taxi [trips/day] & 32 & 33 & 33 & 34 & 35 & 36 \\
\hline Taxi supply [vehicles] & 14425 & 14483 & 14765 & 15072 & 15404 & 15763 \\
\hline Total demand [passengers] & 828593 & 854018 & 880568 & 907905 & 936143 & 965393 \\
\hline
\end{tabular}

\subsection{The scenarios simulation of Harbin taxi operation}

The scenarios selected consider three parameters: fuel price, fare increase and driver wage increase, while these three parameters would affect the interest of operational companies, customers and taxi drivers respectively. Given that, this section sets different classifications of scenarios with the change of taxi fares, fuel prices, and driver wage, in order to simulate the case of taxi operational scenarios in Harbin.
These particular scenarios were chosen in that the following factors were mainly considered:

"»» fuel price changes according to the international oil price changing, which will have an impact on taxi operational companies' operating cost;

"») taxi fare is the direct factor for customer to choose taxi service. Once taxi fare exceeds customers' prospect value, they will choose bus or subway to complete travel;

"») with the economic development in China, the driver wage should increase as the same as the economics growth. 
Therefore this paper had chosen the following particular scenarios to simulate taxi operation of Harbin:

"» fuel prices increase: for fuel prices impact on taxi operations, assuming that fuel prices rises from 6 to $9 ¥ /$ litre, three scenarios were set by step of $1 ¥$ (scenarios I-III);

"») taxi fare increase: as taxi fare include starting fare, distance and fuel surcharge price, the scenarios can be divided into three categories: starting fare increases $1 ¥$, fuel surcharge increases $1 ¥$; and both the starting fare and fuel surcharges increase $1 ¥$. However, embodied in a single trip (assuming an average trip distance per passenger is $5 \mathrm{~km}$ ), there are two different scenarios: namely tariffs were increased by 1 or $2 ¥$ scenarios (scenarios IV and V);

"» both fuel prices and taxi fare rise: such a scenario is similar to the implementation of oil price linkage, in which the oil price for every $1 ¥$ increase, such as the fuel surcharge rise from $1 ¥ /$ times to $2 ¥ /$ times, the concrete can be divided into three scenarios (scenarios VI-VIII);

"» driver wages increase: in recent years, China's Consumer Price Index (CPI) remains a high level, the party and the government also propose to increase income, and improve the well-being. So this paper consider scenario of driver wages increase, which can be divided from $1800 ¥ /$ month increments to $2400 ¥ /$ month by step of per $200 ¥ /$ month divided into three scenarios (scenarios IX-XI).

From these four categories of scenario situations, taxi operation can be simulated as 11 kinds of scenarios, the specific parameter changes are shown in the following Table 5.

The increasing of fuel prices will lead to a decrease of potential passengers and an increase of total taxi supply. While the change time of attractive coefficient, level of service, daily service times per taxi and vacant ratio changes will be relatively slow. Especially in the oil prices rising to $9 ¥ /$ litre, in the simulation period to 60 months, the situa-

Table 5. Classification of taxi operational scenarios

\begin{tabular}{|l|l|c|c|c|}
\cline { 2 - 5 } \multicolumn{1}{c|}{} & \multicolumn{1}{c|}{$\begin{array}{c}\text { Scenarios } \\
\text { categories }\end{array}$} & $\begin{array}{c}\text { Fuel } \\
\text { prices } \\
{[¥ / \text { litre }]}\end{array}$ & $\begin{array}{c}\text { Taxi } \\
\text { fare } \\
{[¥ / \text { time }]}\end{array}$ & $\begin{array}{c}\text { Driver } \\
\text { wages } \\
{[¥ / \text { month] }}\end{array}$ \\
\hline Basal scenario & - & 6 & 13 & 1800 \\
\hline $\begin{array}{l}\text { 1) fuel prices } \\
\text { increase }\end{array}$ & scenario I & 7 & 13 & 1800 \\
\cline { 2 - 5 } & scenario II & 8 & 13 & 1800 \\
\cline { 2 - 5 } & scenario III & 9 & 13 & 1800 \\
\hline \multirow{2}{*}{$\begin{array}{c}\text { 2) taxi fare } \\
\text { increase }\end{array}$} & scenario IV & 6 & 14 & 1800 \\
\cline { 2 - 5 } & scenario V & 6 & 15 & 1800 \\
\hline $\begin{array}{c}\text { 3) both fuel } \\
\text { prices and } \\
\text { taxi fare } \\
\text { rise }\end{array}$ & scenario VI & 7 & 14 & 1800 \\
\cline { 2 - 5 } & scenario VII & 8 & 14 & 1800 \\
\cline { 2 - 5 } & scenario VIII & 9 & 14 & 1800 \\
\hline \multirow{2}{*}{$\begin{array}{c}\text { 4) driver } \\
\text { wages } \\
\text { increase }\end{array}$} & scenario IX & 6 & 13 & 2000 \\
\cline { 2 - 5 } & scenario X & 6 & 13 & 2200 \\
\cline { 2 - 5 } & scenario XI & 6 & 13 & 2400 \\
\hline
\end{tabular}

tion of taxi operator changed only occurs 2 times, and the statistics can be shown in the Appendix (Table A1)

The changes of fuel price will directly decrease taxi operational companies' profit and affect the increasing of new taxi vehicle, then affect the taxi supply, total service time, and level of service. Based on the feedback of Figure 3, the potential demand will increase slowly. The changing of one part of the system will affect all others. The detailed information can be seen in the Appendix ( $\mathrm{Ta}$ bles A2-A5).

As is shown in the statistical data, based on the simulation of the taxi operations under the increase of taxi fare, tariff increase will raise the level of taxi service, reduce vacant ratio and increase daily service times per taxi, which is 37 times in scenario V. The speed of attractive coefficient, total demand and supply increase according to the base scenario.

Then the three scenarios of fuel prices and taxi fare rise were contrasted with that of fuel prices increasing. Simulation results reveals that using price linkage program is useful for taxi companies, because it cannot only increase their income and thus to increase the supply of taxis, but also conducive to decline vacant ratio and improve the level of service.

While the three scenarios of driver wages increase were considered for the salary increase of driver, compared with the base scenario, it will reduce corporate earnings, but slightly, which will not affect the normal increase of the new taxi vehicles. In addition, the actual influence is inferior to the rising of fuel prices.

\subsection{Discussion}

Based on the above simulation results of eleven scenarios, this paper set four kinds of policy guidance proposals from the different stakeholders for the future development of urban taxi market, the details were as follow:

"» increase driver wages to improve the well-being: taxi drivers are the direct providers of taxi service, and they provide passengers with direct service from the origin to the destination. Usually, the drivers work $10 \ldots 12 \mathrm{~h} /$ day. Taking Harbin as an example, $90 \%$ of the taxi drivers work $10 \ldots 15 \mathrm{~h} /$ day, but at the same time, the wage of more than $70 \%$ drivers is below $1,800 ¥$ per month. In recent years taxi drivers’ income has been affected by the rising fuel prices, taxi fuel surcharges and other economic factors. The taxi profit comes from the payment of passengers, which is a kind of exchange with the service from taxi drivers, that is, taxi drivers are the most direct link to create the interests, especially with the rise in prices and living standard, so increasing driver corresponding wages embody distribution according to work will help to improve driver's working initiative. From the simulation results in Tables A1-A5 (in Appendix), the salary increase of drivers will slightly reduce taxi operators' earning, and will not affect the normal increase of the new taxi vehicles, which will meet the passenger's travelling demand; 
") adopting dial-a-ride service to reduce taxi vacant ratio: taxi vehicles cruising on the road has leaded to a higher taxi vacant ratio and larger proportion road space before the introducing dial-a-ride service or taxi-hailing mobile apps in China. For example, the Harbin taxi vacant ratio (in terms of travel distance) is $50.6 \%$ and taxi vehicle volume shares $27 \%$ of the total traffic in 2009 (An et al. 2011). Dial-aride service or taxi-hailing mobile apps can facilitate passenger's travel and save waiting time cost, meanwhile it can reduce taxi travel distance vacant ratio, which will achieve fuel economy, decrease exhaust pollution emissions, and even mitigate road traffic congestion (An et al. 2011; Fu 2002; Qian, Ukkusuri 2017; Santos, Xavier 2015). Dial-a-ride service should have the information network and the corresponding taxi dispatch centre to implement. In June 2014, Harbin Taxi Service Management Information System has been built, which provides a good opportunity for the implementation of dial-a-ride service. With the development of taxi-hailing mobile apps in China, it can also be helpful for the decreasing of taxi vacant ratio (Chen et al. 2017);

"» implement price linkage to share the impact of rising oil prices on corporate: for a taxi, oil prices' going up and down has a direct relationship with costs and benefits, especially in the situation of a rise oil price and taxi price stagnant. If there are no corresponding measures for rational regulation, the enthusiasm of enterprises will be dampened, and illegal means for protect the profits will be taken down, which would undermine the stability and harmony of taxi operators. So establishing dynamic oil prices mechanism, changing oil price from only the responsibility of enterprises into a shared, multi-stakeholder, or giving the appropriate subsidies to reduce or even avoiding the floating oil price impact on the business will provide a good environment for the development of enterprises;

") increasing taxi number timely to meet the passenger travel needs: the total taxi number in Harbin downtown are not less than similar size cities, however, considering the Harbin long and cold winter weather conditions, as an effective complement to the bus, taxi is an important way for people to travel on, so number of taxi should be increased to meet the needs of multi-level passenger.

\section{Conclusions}

This paper determined the relationship among these 4 categories of stakeholders: (1) administrative department, (2) operational companies, (3) taxi drivers and (4) customers. Then we adopted SD approach to describe the complex nature of urban taxi system, which had considered the relationship among the various stakeholders. The model first incorporated the four categories of taxi system's stakeholders, and then combined survey data of Harbin taxi service to simulate kinds of operation scenarios. Based on the simulation results, this paper discussed kinds of methods to improve the urban taxi transportation system. This SD model can provide structure and scope to the urban taxi industry as well as to the taxi development planner.

Then the paper explored the varying variable sensitivity analysis with respect to prices, and found that the fuel price increasing will slow down the customer demand; the price linkage program will be benefit for the taxi companies because of a reasonable share for the fuel price increasing. Meanwhile, the taxi drivers' wage increasing will be helpful for the drivers and not affect the normal increase of new taxi vehicles.

After considering the simulation results, we proposed future development policies and recommendations for the Harbin taxi market, including four specific methods. Firstly, increasing driver wages is recommended as it will improve driver's working initiative from a certain level, then help satisfy passengers' travel demand. Secondly, adopting dial-a-ride service may be a useful suggestion because this method can aid passengers to travel and save waiting time cost; meanwhile it can achieve fuel economy and decrease exhaust pollution emissions. Thirdly, it is advised to implement oil price linkage to help establish oil-price mechanism. What's more, timely inputting new capacity to meet passengers' travel needs is recommended. In addition, others recommendations like taxi stop setting better and so on may be taken into consideration. Overall, these recommendations can not only provide structure and scope to the industry, but also can be useful for the planner in developing the urban taxi price.

The application of SD approach in urban taxi price has provided a new view to identify the relationship among urban taxi system; this application has potential transferability to the whole transport system of city, which will integrate kinds of mode (bus, taxi, subway, private car and logistics), as well as reveal the relationship and feedback among the system, which will be conducive to the coordination, health and sustainable development of urban transport system.

In the future research, we will consider the deployment of electric taxis to reduce taxi air pollution emission (Yang et al. 2016), as well as the competition with the Internet booking taxi by the taxi-hailing apps into this taxi operation SD model. Furthermore, with the development of data-driven approach applied to analyse the massive trajectory data of taxi vehicles, we can obtain the different travel demand in different districts in the city. In addition, combined with the population and land use, this different travel demand can provide a better analysis angle for urban taxi operation and urban planning.

\section{Acknowledgements}

This research was supported by the

"» National Natural Science Foundation of China (Grants No 71603063, 91846301);

"» Natural Science Foundation of Heilongjiang (Grant No E2016032). 


\section{Appendix}

Table A1. The statistics of time node changes for taxi operation simulation

\begin{tabular}{|c|c|c|c|c|c|c|}
\hline & $\begin{array}{l}\text { Scenarios } \\
\text { categories }\end{array}$ & $\begin{array}{l}\text { Month of 1st } \\
\text { change }\end{array}$ & $\begin{array}{l}\text { Month of 2nd } \\
\text { change }\end{array}$ & $\begin{array}{l}\text { Month of } 3 \mathrm{rd} \\
\text { change }\end{array}$ & $\begin{array}{l}\text { Month of } 4 \text { th } \\
\text { change }\end{array}$ & $\begin{array}{l}\text { Month of 5th } \\
\text { change }\end{array}$ \\
\hline Basal scenario & - & 10 & 29 & 45 & 60 & - \\
\hline \multirow{3}{*}{$\begin{array}{l}\text { 1) fuel prices } \\
\text { increase }\end{array}$} & scenario I & 11 & 32 & 50 & - & - \\
\hline & scenario II & 12 & 36 & 55 & - & - \\
\hline & scenario III & 16 & 41 & - & - & - \\
\hline \multirow[t]{2}{*}{ 2) taxi fare increase } & scenario IV & 8 & 23 & 37 & 50 & \\
\hline & scenario V & 7 & 20 & 31 & 42 & 53 \\
\hline \multirow{3}{*}{$\begin{array}{l}\text { 3) both fuel prices } \\
\text { and taxi fare rise }\end{array}$} & scenario VI & 9 & 26 & 40 & 54 & - \\
\hline & scenario VII & 10 & 28 & 44 & 58 & - \\
\hline & scenario VIII & 11 & 31 & 48 & - & - \\
\hline \multirow{3}{*}{$\begin{array}{l}\text { 4) driver wages } \\
\text { increase }\end{array}$} & scenario IX & 11 & 30 & 47 & - & - \\
\hline & scenario $\mathrm{X}$ & 11 & 31 & 48 & - & - \\
\hline & scenario XI & 12 & 32 & 50 & - & - \\
\hline
\end{tabular}

Table A2. The statistics of daily service trips per taxi for taxi operation simulation

\begin{tabular}{|c|c|c|c|c|c|c|}
\hline & $\begin{array}{l}\text { Scenarios } \\
\text { categories }\end{array}$ & Year 1 & Year 2 & Year 3 & Year 4 & Year 5 \\
\hline Basal scenario & - & 33 & 33 & 34 & 35 & 36 \\
\hline \multirow{3}{*}{$\begin{array}{l}\text { 1) fuel prices } \\
\text { increase }\end{array}$} & scenario I & 33 & 33 & 34 & 34 & 35 \\
\hline & scenario II & 32 & 33 & 34 & 34 & 35 \\
\hline & scenario III & 32 & 33 & 33 & 34 & 34 \\
\hline \multirow[t]{2}{*}{ 2) taxi fare increase } & scenario IV & 33 & 34 & 34 & 35 & 36 \\
\hline & scenario $\mathrm{V}$ & 33 & 34 & 35 & 36 & 37 \\
\hline \multirow{3}{*}{$\begin{array}{l}\text { 3) both fuel prices } \\
\text { and taxi fare rise }\end{array}$} & scenario VI & 33 & 33 & 34 & 35 & 36 \\
\hline & scenario VII & 33 & 33 & 34 & 35 & 36 \\
\hline & scenario VIII & 33 & 33 & 34 & 35 & 35 \\
\hline \multirow{3}{*}{$\begin{array}{l}\text { 4) driver wages } \\
\text { increase }\end{array}$} & scenario IX & 33 & 33 & 34 & 35 & 35 \\
\hline & scenario $\mathrm{X}$ & 33 & 33 & 34 & 35 & 35 \\
\hline & scenario XI & 33 & 33 & 34 & 34 & 35 \\
\hline
\end{tabular}

Table A3. The statistics of level of service for taxi operation simulation

\begin{tabular}{|l|l|l|l|l|l|c|}
\cline { 2 - 7 } \multicolumn{1}{c|}{} & \multicolumn{1}{c|}{$\begin{array}{c}\text { Scenarios } \\
\text { categories }\end{array}$} & Year 1 & Year 2 & Year 3 & Year 4 & Year 5 \\
\hline Basal scenario & \multicolumn{1}{c|}{-} & 0.60625 & 0.60625 & 0.61250 & 0.61875 & 0.62500 \\
\hline \multirow{2}{*}{$\begin{array}{c}\text { 1) fuel prices } \\
\text { increase }\end{array}$} & scenario I & 0.60625 & 0.60625 & 0.61250 & 0.61250 & 0.61875 \\
\cline { 2 - 7 } & scenario II & 0.60000 & 0.60625 & 0.61250 & 0.61250 & 0.61875 \\
\cline { 2 - 8 } & scenario III & 0.60000 & 0.60625 & 0.60625 & 0.61250 & 0.61250 \\
\hline \multirow{2}{*}{$\begin{array}{c}\text { 2) taxi fare increase } \\
\text { 3) both fuel prices } \\
\text { and taxi fare rise }\end{array}$} & scenario IV & 0.60625 & 0.61250 & 0.61250 & 0.61875 & 0.62500 \\
\cline { 2 - 8 } & scenario V & 0.60625 & 0.61250 & 0.61875 & 0.62500 & 0.63125 \\
\cline { 2 - 8 } & scenario VI & 0.60625 & 0.60625 & 0.61250 & 0.61875 & 0.62500 \\
\cline { 2 - 8 } & scenario VII & 0.60625 & 0.60625 & 0.61250 & 0.61875 & 0.62500 \\
\hline \multirow{2}{*}{$\begin{array}{c}\text { 4) driver wages } \\
\text { increase }\end{array}$} & scenario IX & 0.60625 & 0.60625 & 0.61250 & 0.61875 & 0.61875 \\
\cline { 2 - 8 } & scenario X & 0.60625 & 0.60625 & 0.61250 & 0.61875 & 0.61875 \\
\cline { 2 - 8 } & scenario XI & 0.60625 & 0.60625 & 0.61250 & 0.61250 & 0.61875 \\
\hline
\end{tabular}


Table A4. The statistics of taxi supply for taxi operation simulation

\begin{tabular}{|c|c|c|c|c|c|c|}
\hline & $\begin{array}{l}\text { Scenarios } \\
\text { categories }\end{array}$ & Year 1 & Year 2 & Year 3 & Year 4 & Year 5 \\
\hline Basal scenario & - & 14483 & 14765 & 15072 & 15404 & 15763 \\
\hline \multirow{3}{*}{$\begin{array}{l}\text { 1) fuel prices } \\
\text { increase }\end{array}$} & scenario I & 14452 & 14703 & 14979 & 15279 & 15605 \\
\hline & scenario II & 14421 & 14642 & 14886 & 15155 & 15449 \\
\hline & scenario III & 14390 & 14580 & 14794 & 15032 & 15294 \\
\hline \multirow[t]{2}{*}{ 2) taxi fare increase } & scenario IV & 14552 & 14907 & 15291 & 15704 & 16149 \\
\hline & scenario $\mathrm{V}$ & 14621 & 15049 & 15511 & 16007 & 16540 \\
\hline \multirow{3}{*}{$\begin{array}{l}\text { 3) both fuel prices } \\
\text { and taxi fare rise }\end{array}$} & scenario VI & 14521 & 14845 & 15197 & 15578 & 15988 \\
\hline & scenario VII & 14490 & 14783 & 15103 & 15452 & 15830 \\
\hline & scenario VIII & 14459 & 14721 & 15011 & 15328 & 15674 \\
\hline \multirow{3}{*}{$\begin{array}{l}\text { 4) driver wages } \\
\text { increase }\end{array}$} & scenario IX & 14472 & 14744 & 15040 & 15362 & 15709 \\
\hline & scenario $\mathrm{X}$ & 14461 & 14722 & 15008 & 15319 & 15657 \\
\hline & scenario XI & 14450 & 14701 & 14976 & 15277 & 15603 \\
\hline
\end{tabular}

Table A5. The statistics of vacant ratio for taxi operation simulation

\begin{tabular}{|l|l|l|l|l|l|c|}
\cline { 2 - 7 } \multicolumn{1}{c|}{} & \multicolumn{1}{c|}{$\begin{array}{c}\text { Scenarios } \\
\text { categories }\end{array}$} & Year 1 & Year 2 & Year 3 & Year 4 & Year 5 \\
\hline Basal scenario & \multicolumn{1}{c|}{-} & 0.484375 & 0.484375 & 0.468750 & 0.453125 & 0.437500 \\
\hline \multirow{2}{*}{$\begin{array}{c}\text { 1) fuel prices } \\
\text { increase }\end{array}$} & scenario I & 0.484375 & 0.484375 & 0.468750 & 0.468750 & 0.453125 \\
\cline { 2 - 7 } & scenario II & 0.500000 & 0.484375 & 0.468750 & 0.468750 & 0.453125 \\
\cline { 2 - 8 } & scenario III & 0.500000 & 0.484375 & 0.484375 & 0.468750 & 0.4687500 \\
\hline \multirow{2}{*}{$\begin{array}{c}\text { 2) taxi fare increase } \\
\text { 3) both fuel prices } \\
\text { and taxi fare rise }\end{array}$} & scenario IV & 0.484375 & 0.468750 & 0.468750 & 0.453125 & 0.437500 \\
\cline { 2 - 8 } & scenario V & 0.484375 & 0.468750 & 0.453125 & 0.437500 & 0.421875 \\
\cline { 2 - 8 } & scenario VI & 0.484375 & 0.484375 & 0.468750 & 0.453125 & 0.437500 \\
\hline & scenario VII & 0.484375 & 0.484375 & 0.468750 & 0.453125 & 0.437500 \\
\hline \multirow{2}{*}{$\begin{array}{c}\text { 4) driver wages } \\
\text { increase }\end{array}$} & scenario VIII & 0.484375 & 0.484375 & 0.468750 & 0.453125 & 0.453125 \\
\cline { 2 - 8 } & scenario IX & 0.484375 & 0.484375 & 0.468750 & 0.453125 & 0.453125 \\
\cline { 2 - 8 } & scenario XI & 0.484375 & 0.484375 & 0.468750 & 0.468750 & 0.453125 \\
\hline
\end{tabular}

\section{References}

Abbas, K. A.; Bell, M. G. H. 1994. System dynamics applicability to transportation modeling, Transportation Research Part A: Policy and Practice 28(5): 373-390. https://doi.org/10.1016/0965-8564(94)90022-1

An, S.; Hu, X.; Wang, J. 2011. Urban taxis and air pollution: a case study in Harbin, China, Journal of Transport Geography 19(4): 960-967. https://doi.org/10.1016/j.jtrangeo.2010.12.005

Arnott, R. 1996. Taxi travel should be subsidized, Journal of Urban Economics 40(3): 316-333. https://doi.org/10.1006/juec.1996.0035

Barlas, Y. 2007. Leverage points to march "upward from the aimless plateau”, System Dynamics Review 23(4): 469-473. https://doi.org/10.1002/sdr.389

Cairns, R. D.; Liston-Heyes, C. 1996. Competition and regulation in the taxi industry, Journal of Public Economics 59(1): 1-15. https://doi.org/10.1016/004-2727(94)01495-7

Chen, X.; Zahiri, M.; Zhang, S. 2017. Understanding ridesplitting behavior of on-demand ride services: an ensemble learning approach, Transportation Research Part C: Emerging Technologies 76: 51-70. https://doi.org/10.1016/j.trc.2016.12.018
Cooper, J.; Mundy, R. 2010. Taxi! Urban Economies and the Social and Transport Impacts of the Taxicab. Routledge. 208 p. https://doi.org/10.4324/9781315611884

De Vany, A. S. 1975. Capacity utilization under alternative regulatory restraints: an analysis of taxi markets, Journal of Political Economy 83(1): 83-94. https://doi.org/10.1086/260307

Dempsey, P. S. 1996. Taxi industry regulation, deregulation \& reregulation: the paradox of market failure, Transportation Law Journal 24: 73-120.

Drăgoicea, M.; Falcão e Cunha, J.; Pătraşcu, M. 2015. Self-organising socio-technical description in service systems for supporting smart user decisions in public transport, Expert Systems with Applications 42(17-18): 6329-6341. https://doi.org/10.1016/j.eswa.2015.04.029

Drew, D. R. 1990. System dynamics modeling of development induced by transportation investment, Transportation Research Record 1274: 63-81.

Federici, M.; Ulgiati, S.; Verdesca, D.; Basosi, R. 2003. Efficiency and sustainability indicators for passenger and commodities transportation systems: the case of Siena, Italy, Ecological Indicators 3(3): 155-169.

https://doi.org/10.1016/S1470-160X(03)00040-2 
Fu, L. 2002. Scheduling dial-a-ride paratransit under time-varying, stochastic congestion, Transportation Research Part B: Methodological 36(6): 485-506.

https://doi.org/10.1016/S0191-2615(01)00014-5

Gaunt, C.; Black, T. 1996. The economic cost of taxicab regulation: the case of Brisbane, Economic Analysis and Policy 26(1): 45-58. https://doi.org/10.1016/S0313-5926(96)50003-2

Gärling, T.; Laitila, T.; Marell, A.; Westin, K. 1995. A note on the short-term effects of deregulation of the Swedish taxi-cab industry, Journal of Transport Economics and Policy 29(2): 209-214.

Haghani, A.; Lee, S. Y.; Byun, J. H. 2002. A system dynamics approach to land use/transportation system performance modelling. Part I: methodology, Journal of Advanced Transportation 37(1): 1-41. https://doi.org/10.1002/atr.5670370102

Han, B.; Nie, W.; He, L. 2010. Research on Taxi Market System: Theory and Practice. China Communications Press, Beijing. (in Chinese).

Han, J.; Hayashi, Y. 2008. A system dynamics model of $\mathrm{CO}_{2}$ mitigation in China's inter-city passenger transport, Transportation Research Part D: Transport and Environment 13(5): 298-305. https://doi.org/10.1016/j.trd.2008.03.005

Han, S. S. 2010. Managing motorization in sustainable transport planning: the Singapore experience, Journal of Transport Geography 18(2): 314-321. https://doi.org/10.1016/j.jtrangeo.2009.06.010

Hang, W.; Li, X. 2010. Application of system dynamics for evaluating truck weight regulations, Transport Policy 17(4): 240250. https://doi.org/10.1016/j.tranpol.2010.01.007

Häckner, J.; Nyberg, S. 1995. Deregulating taxi services: a word of caution, Journal of Transport Economics and Policy 29(2): 195-207.

Kim, H.; Yang, I.; Choi, K. 2011. An agent-based simulation model for analyzing the impact of asymmetric passenger demand on taxi service, KSCE Journal of Civil Engineering 15(1): 187-195. https://doi.org/10.1007/s12205-011-1037-8

Liu, S.; Triantis, K. P.; Sarangi, S. 2010. A framework for evaluating the dynamic impacts of a congestion pricing policy for a transportation socioeconomic system, Transportation Research Part A: Policy and Practice 44(8): 596-608. https://doi.org/10.1016/j.tra.2010.04.001

Lv, H. 2011. Research on Urban Passenger Taxi Pricing Based on System Dynamic. Dissertation. Harbin Institute of Technology, Harbin, China. (in Chinese).

Minato, N.; Morimoto, R. 2011. Designing the commercial sustainability of unprofitable regional airports using system dynamics analysis, Research in Transportation Business \& Management 1(1): 80-90.

https://doi.org/10.1016/j.rtbm.2011.06.009

Morrison, P. S. 1997. Restructuring effects of deregulation: the case of the New Zealand taxi industry, Environment and Planning A: Economy and Space 29(5): 913-928. https://doi.org/10.1068/a290913

Qian, X.; Ukkusuri, S. V. 2015. Spatial variation of the urban taxi ridership using GPS data, Applied Geography 59: 31-42. https://doi.org/10.1016/j.apgeog.2015.02.011

Qian, X.; Ukkusuri, S. V. 2017. Taxi market equilibrium with third-party hailing service, Transportation Research Part B: Methodological 100: 43-63. https://doi.org/10.1016/j.trb.2017.01.012

Roumboutsos, A.; Kapros, S. 2008. A game theory approach to urban public transport integration policy, Transport Policy 15(4): 209-215. https://doi.org/10.1016/j.tranpol.2008.05.001
Santos, D. O.; Xavier, E. C. 2015. Taxi and ride sharing: a dynamic dial-a-ride problem with money as an incentive, $E x$ pert Systems with Applications 42(19): 6728-6737. https://doi.org/10.1016/j.eswa.2015.04.060

Schaller, B. 1999. Elasticities for taxicab fares and service availability, Transportation 26(3): 283-297. https://doi.org/10.1023/A:1005185421575

Simões, P.; Marques, R. C. 2010. Seaport performance analysis using robust non-parametric efficiency estimators, Transportation Planning and Technology 33(5): 435-451. https://doi.org/10.1080/03081060.2010.502375

Song, C. 2010. Resident trip characteristics comparison in main cities among three city circles of China, Traffic \& Transportation (z1): 1-4. (in Chinese).

STSE. 2009. The Report of Harbin Taxi Operating Survey Analysis. School of Transportation Science and Engineering (STSE), Harbin Institute of Technology, Harbin, China. (in Chinese).

Van de Velde, D. M. 1999. Organisational forms and entrepreneurship in public transport: classifying organisational forms, Transport Policy 6(3): 147-157. https://doi.org/10.1016/S0967-070X(99)00016-5

Wang, H. 2011. A Practice of Smart City: Intelligent Taxi Dispatch Services with Real-Time Traffic and Customer Information. Beihang University Press, Beijing, China. (in Chinese).

Wang, J.; Chen, X.-W. 2004. Analyzing the pricing mechanism of the taxi service with economics theory, Journal of Transportation Engineering and Information (4): 99-104. (in Chinese).

Wang, Y. 2009. Taxi market related stakeholders' interest and the best operational mode analysis, Probe (1): 137-142. (in Chinese).

Yang, H.; Leung, C. W. Y.; Wong, S. C.; Bell, M. G. H. 2010. Equilibria of bilateral taxi-customer searching and meeting on networks, Transportation Research Part B: Methodological 44(8-9): 1067-1083. https://doi.org/10.1016/j.trb.2009.12.010

Yang, H., Wong, S. C., Wong, K. I. 2002. Demand-supply equilibrium of taxi services in a network under competition and regulation, Transportation Research Part B: Methodological 36(9): 799-819. https://doi.org/10.1016/S0191-2615(01)00031-5

Yang, H.; Yang, T. 2011. Equilibrium properties of taxi markets with search frictions, Transportation Research Part B: Methodological 45(4): 696-713.

https://doi.org/10.1016/j.trb.2011.01.002

Yang, H., Ye, M., Tang, W. H., Wong, S. C. 2005. Regulating taxi services in the presence of congestion externality, Transportation Research Part A: Policy and Practice 39(1): 17-40. https://doi.org/10.1016/j.tra.2004.05.004

Yang, J.; Dong, J.; Lin, Z.; Hu, L. 2016. Predicting market potential and environmental benefits of deploying electric taxis in Nanjing, China, Transportation Research Part D: Transport and Environment 49: 68-81. https://doi.org/10.1016/j.trd.2016.08.037 